\title{
Evaluation of Some Coagulation Profile and Estimation of Fibrinogen Level in Sudanese Patients with Type II Diabetes Mellitus
}

\author{
Amged Husssien Abdelrhman*, Abdegadir Ahmed Abdelgadir \\ Department of Hematology and Immunohematology, Omdurman Islamic University, Sudan.
}

\begin{abstract}
How to cite this paper: Amged Husssien Abdelrhman, Abdegadir Ahmed Abdelgadir. (2020) Evaluation of Some Coagulation Profile and Estimation of Fibrinogen Level in Sudanese Patients with Type II Diabetes Mellitus. International Journal of Clinical and Experimental Medicine Research, 4(4), 138-144. DOI: $10.26855 /$ ijcemr.2020.10.004

Received: July 20, 2020

Accepted: August 12, 2020

Published: August 20, 2020

*Corresponding author: Amged Husssien Abdelrhman, Department of Hematology and Immunohematology, Omdurman Islamic University, Sudan. Email: Amgedhussen66@gmail.com
\end{abstract}

\begin{abstract}
Background: Type II diabetes, fibrinogen levels have been demonstrated to predict the progression to overt nephropathy. Hyperfibrinogenemia, an indicator of inflammation, is also associated with the presence of endothelial dysfunction, insulin resistance, hypercoagulability, and increased blood viscosity and is a marker of unstable atherosclerotic lesions. Aim: This study aimed to evaluation of coagulation profile and D. Dimer and estimation of Serum Fibrinogen Level in Sudanese Patients with type II Diabetes Mellitus in Khartoum State. Methods: A questionnaire was designed to collect information about the study group, Blood sample were collected from all participants in Tri sodium citrate containers. Automated coagulometer (COATRON M1) was used to evaluate prothrombine time and activated partial thromboplastine time and measure fibrinogen level. D-dimer levels were evaluated using (ichroma ${ }^{\mathrm{TM}}$ ) Reader fluorescence scanning instrument an integrated Point of Care Test (P.O.C.T.) system. Results: The study showed that the mean and Std of PT, APTT, INR was $(17.9 \pm 3.8 \mathrm{sec}, 32.6 \pm 4.1 \mathrm{sec}$, $1.1 \pm 0.3$ respectively), the mean of age among study group was $(53 \pm 14.2$ years), there was significant different when correlate PT and management of disease (p. value 0.01). Conclusion: The present study show that shortened prothrombin time, activated partial thromboplastin time, shortened PT and APTT might be useful hemostatic markers in diabetic patients, especially in those at high risk for thrombotic complications.
\end{abstract}

\section{Keywords}

Coagulation profile, Fibrinogen, Type II D. M

\section{Introduction}

The concept of blood coagulation dates back to 1960 when Davie, Ratnoff and Macfarlane described the "waterfall" and "cascade" theories outlining the fundamental principle of cascade of pro-enzymes leading to activation of downstream enzymes [1]. Haemostasis, defined as arrest of bleeding, comes from Greek, haeme meaning blood and stasis meaning to stop [2]. Thrombohaemmorhagic balance is maintained in the body by complicated interaction between coagulation and fibrinolytic system as well as platelets and vessel wall. Usually, the coagulation processes under the inhibitory control of several inhibitors that limit the clot formation, avoiding thrombus propagation. This delicate balance is interrupted whenever the pro-coagulant activity of the coagulation factors is increased, or the activity of naturally occurring inhibitors is decreased [3]. (DM) is a metabolic disorder 
characterized by chronic hyperglycemia due to disturbances of carbohydrate, fat, and protein metabolism that are associated with absolute or relative deficiencies in insulin secretion, insulin action or both (Charles, 1998). Diabetes have three main types: type one diabetes mellitus which called (IDDM), type two diabetes mellitus which called (NIDDM) and gestational diabetes which is classified as type two diabetes mellitus. The long term affects and complications of diabetes include progressive development of the retinopathy, and neuropathy with micro vascular and macro vascular diseases. Macrovascular disorders such as atherosclerosis are recognized as a major cause of mortality in diabetic population, and are implicated in the circulatory disturbances that are seen in diabetes. The circulatory disturbances are further complicated by alteration in platelet count and activity, coagulopathy, fibrinolytic aberration, haemorrheological factors, and changes endothelial metabolism [4]. Many studies have shown that diabetes is a hypercoagulable state. Hypercoagulability results from enhanced vascular endothelial cell expression of tissue factor and Von Willebrand factor. Other factors include increased platelet adhesiveness, elevated level of procoagulant factor and decreased fibrinolytic activity [5].

\section{Materials and Methods}

\section{Sample Collection and Sample Techniques}

Venous blood sample was collected using sterile plastic syringe after cleaning the venipuncture area with $70 \%$ ethanol, the blood was added to the anticoagulant at ratio of 9.1 to $0.5 \mathrm{ml}$ of tri sodium citrate $[3.2 \%(0.109 \mathrm{M})]$ buffered sodium citrate and gently mixed. The sample was centrifuge at $4.500 \mathrm{rpm}$ for $15 \mathrm{~min}$ to obtain platelet poor plasma (ppp). The ppp placed into plastic tube. The PT, APTT and fibrinogen level was measured using the Automated Coagulometer Analyzer. This Fibrinogen test based upon the Fibrinogen antigen-antibody reaction. D-Dimer levels were evaluated using ichroma ${ }^{\mathrm{TM}}$ Reader fluorescence scanning instrument an integrated Point of Care Test (P.O.C.T.) system.

\section{Results}

In the present study, the frequency of mean and STD of PT among study group (17.9) (3.8\%), APTT (32.6) (4.1\%), INR (1.1) $(0.3 \%)$ in Table 1. In the present study, there is insignificant association between PT and treatment and gender p. value (0.193) in Table 2, insignificant association between APTT and management, hypertension, treatment and gender was observed p. value $(0.197,0.34,0.39,0.21)$ respectively in Table 3 . In this study, there is significant positive correlation between the age and PT result. P. value 0.05 in Figure 1 and significant positive correlation between the age and APTT, p. value 0.02 in Figure 2. The result shows the mean \pm SD of age among study group was ( $47 \pm 16.6$ years), the mean \pm SD of duration of the disease was ( $7.6 \pm 3.1$ years) and the mean \pm SD of fibrinogen level was $136 \pm 20.7$, the frequency of male $50 \%$ and female $50 \%$ in Table 4 . The mean of the fibrinogen level among the study group that different between male and female, the mean \pm SD of fibrinogen level in male was $137.4 \pm 20.6 \mathrm{mg} / \mathrm{dl}$ and in female was $135.22 \pm 20.9 \mathrm{mg} / \mathrm{dl}$. The present study shows the insignifcant correlation among gender P. value was (0.594) in Table 5. 98\% of the study shows fibrinogen level than $180 \mathrm{mg} / \mathrm{dl}$ and $2 \%$ more than $180 \mathrm{mg} / \mathrm{dl}$ in Figure 3. The frequency of duration of disease in group less than 5 years was $(34 \%)$, in $5-10$ years was $(41 \%)$ and in group more than 10 years was (25\%). Statistical insignificant differences between fibrinogen level and duration of disease were observed p. value (0.776) in Table 6. In present study, there was an increase in D-Dimer level, mean $(1,309.3 \pm 324.1 \mathrm{ng} / \mathrm{mL}$ ), (D-dimer normal values: $<250 \mathrm{ng} / \mathrm{ml}$ ), in Table 7. The mean of D-Dimer levels in subjects with no other complications and subjects with hypertension was $(2,267.3 \pm 642.3 \mathrm{ng} / \mathrm{mL})$, and showed significant statistical correlation $(\mathrm{P}$. value $=0.033)$, in Table 8.

Table 1. Mean and STD of PT, PTT, INR and age

\begin{tabular}{ccc}
\hline Parameter & Mean & Std \\
\hline PT & $17.9 \mathrm{Sec}$ & 3.8 \\
APTT & $32.6 \mathrm{Sec}$ & 4.1 \\
INR & 1.1 & 0.3 \\
Age & 52.7 years & 14.2 \\
\hline
\end{tabular}


Table 2. Comparison of PT \& APTT according to treatment among study population

\begin{tabular}{|c|c|c|c|c|c|}
\hline Parameters & \multicolumn{3}{|c|}{ Treatment (Mean \pm SD) } & \multicolumn{2}{|c|}{ P. value } \\
\hline PT (second) & \multicolumn{3}{|c|}{$17.6 \pm 3.8$} & \multicolumn{2}{|r|}{0.020} \\
\hline APTT (second) & \multicolumn{3}{|c|}{$32.6 \pm 4.1$} & \multicolumn{2}{|r|}{0.39} \\
\hline \multicolumn{6}{|c|}{ Table 3. Descriptive Statistics of study variables } \\
\hline & $\mathbf{N}$ & Minimum & Maximum & Mean & Std. Deviation \\
\hline Age (years) & 100 & 16 & 77 & 47.3 & 16.6 \\
\hline $\begin{array}{c}\text { Fibrinogen level } \\
\text { (mg|dl) }\end{array}$ & 100 & 99 & 189 & 136.3 & 20.7 \\
\hline Duration (years) & 100 & 3 & 12 & 7.6 & 3.1 \\
\hline
\end{tabular}

Table 4. Correlation between Fibrinogen level among gender

\begin{tabular}{cccc}
\hline \multirow{2}{*}{ Parameters } & \multicolumn{2}{c}{ Gender (Mean \pm SD) } & P. value \\
& Male (n=50) & Female (n=50) & 0.594 \\
\hline Fibrinogen level $(\mathrm{mg} \backslash \mathrm{dl})$ & $137.4 \pm 20.6$ & $135.22 \pm 20.9$ & \\
\hline Table 5. Comparison of Fibrinogen level among duration of disease group & Fibrinogen (Mean \pm SD) & P. value \\
\hline Duration of disease & Frequency & $137.4 \pm 22.7$ & 0.776 \\
\hline Less than 5 years & 34 & $134.6 \pm 21.5$ & $137.8 \pm 16.9$ \\
\hline
\end{tabular}

Table 6. Comparison of Fibrinogen level among age group

\begin{tabular}{cccc}
\hline Age groups & Frequency & Fibrinogen $($ Mean \pm SD) & P. value \\
\hline Less than 20 years & 8 & $142.6 \pm 27.1$ \\
20-30 years & 14 & $136.7 \pm 226$ \\
31-40 years & 10 & $131.7 \pm 27.4$ & $137.3 \pm 20.8$ \\
41-50 years & 19 & $139.7 \pm 16.1$ & 0.667 \\
50-60 years & 22 & $130.3 \pm 16.9$ & $142.4 \pm 25.9$ \\
61-70 years & 22 & 5 \\
\hline
\end{tabular}

Table 7. Mean of D-Dimer among study group

\begin{tabular}{cccccc}
\hline & N & Minimum & Maximum & Mean & Std. Deviation \\
\hline D-dimer & 100 & 133.9 & $6,706.4$ & $1,517.3$ & 373.5 \\
\hline
\end{tabular}

Table 8. Comparison of D-Dimer levels with no other complications and with hypertension

\begin{tabular}{cccc}
\hline \multirow{2}{*}{ Parameter } & \multicolumn{2}{c}{ Population study } & P. value \\
& No other disease $(\mathbf{n}=\mathbf{5 0})$ & Hypertension (n=50) & 0.033 \\
\hline D-Dimer & $2,267.3 \pm 642.3$ & $7,048.5 \pm 611.1$ & 0.1 \\
\hline
\end{tabular}




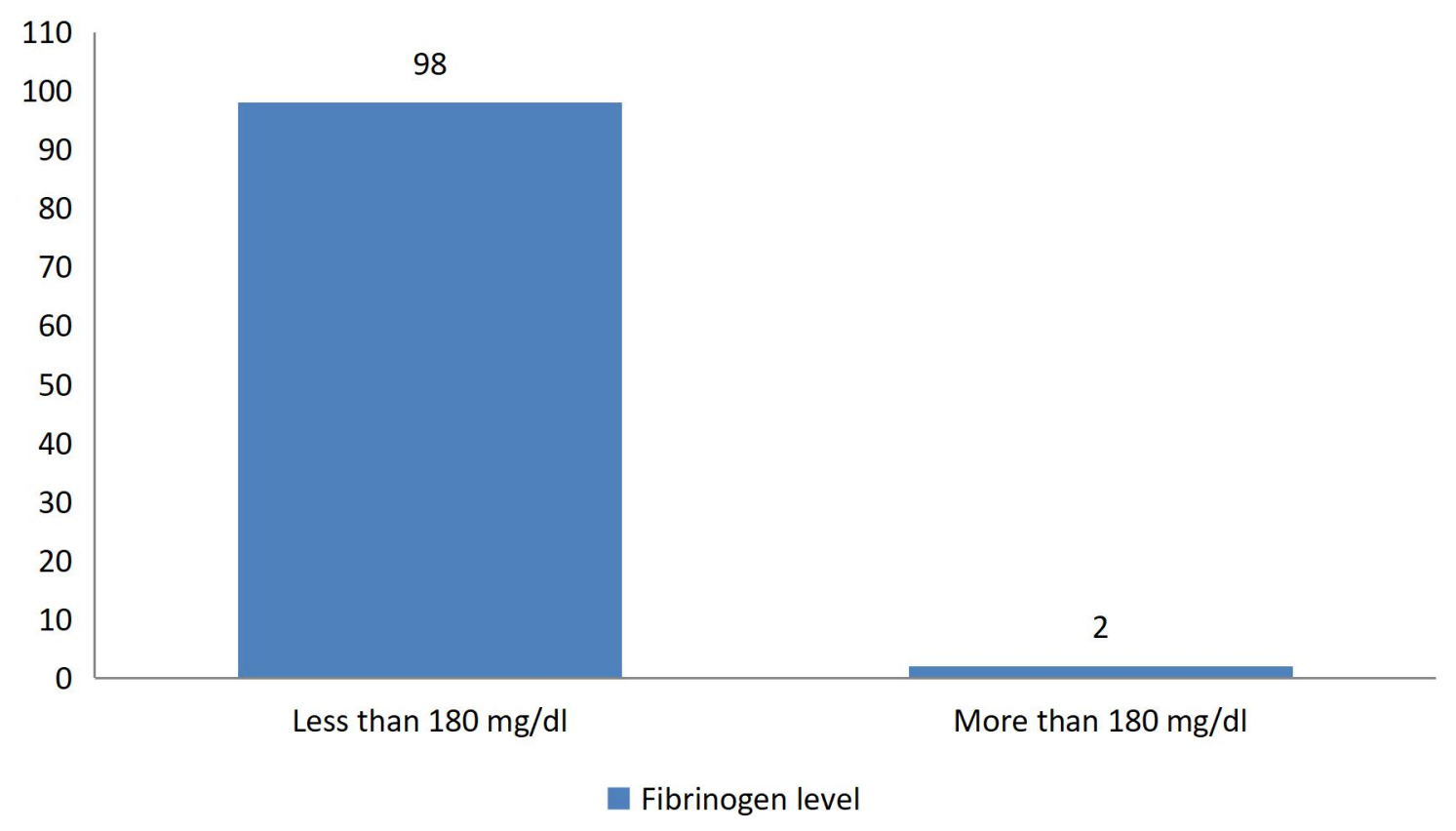

Figure 1. Frequency of fibrinogen level among study group.

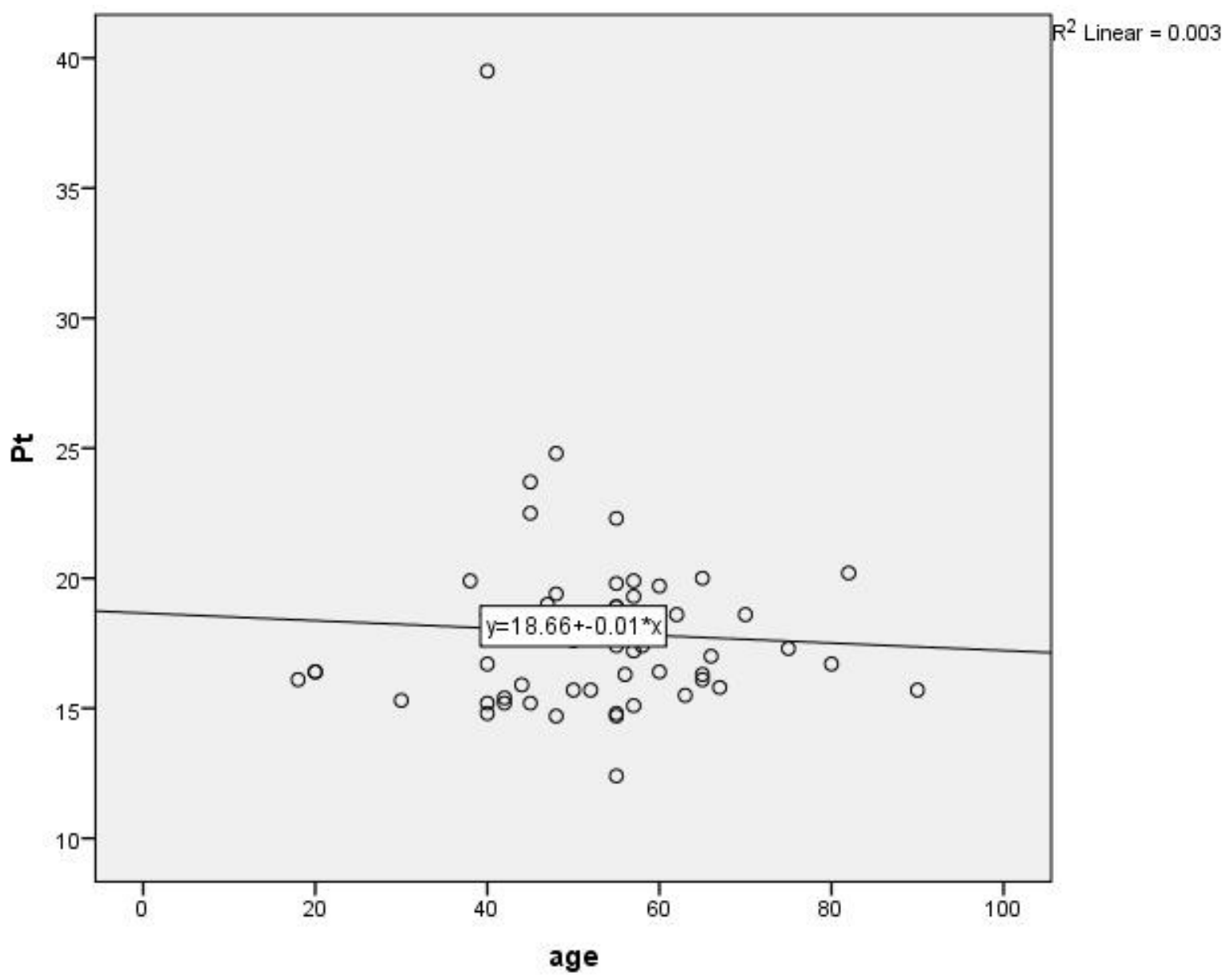

Figure 2. Positive Correlation between PT result and age. 


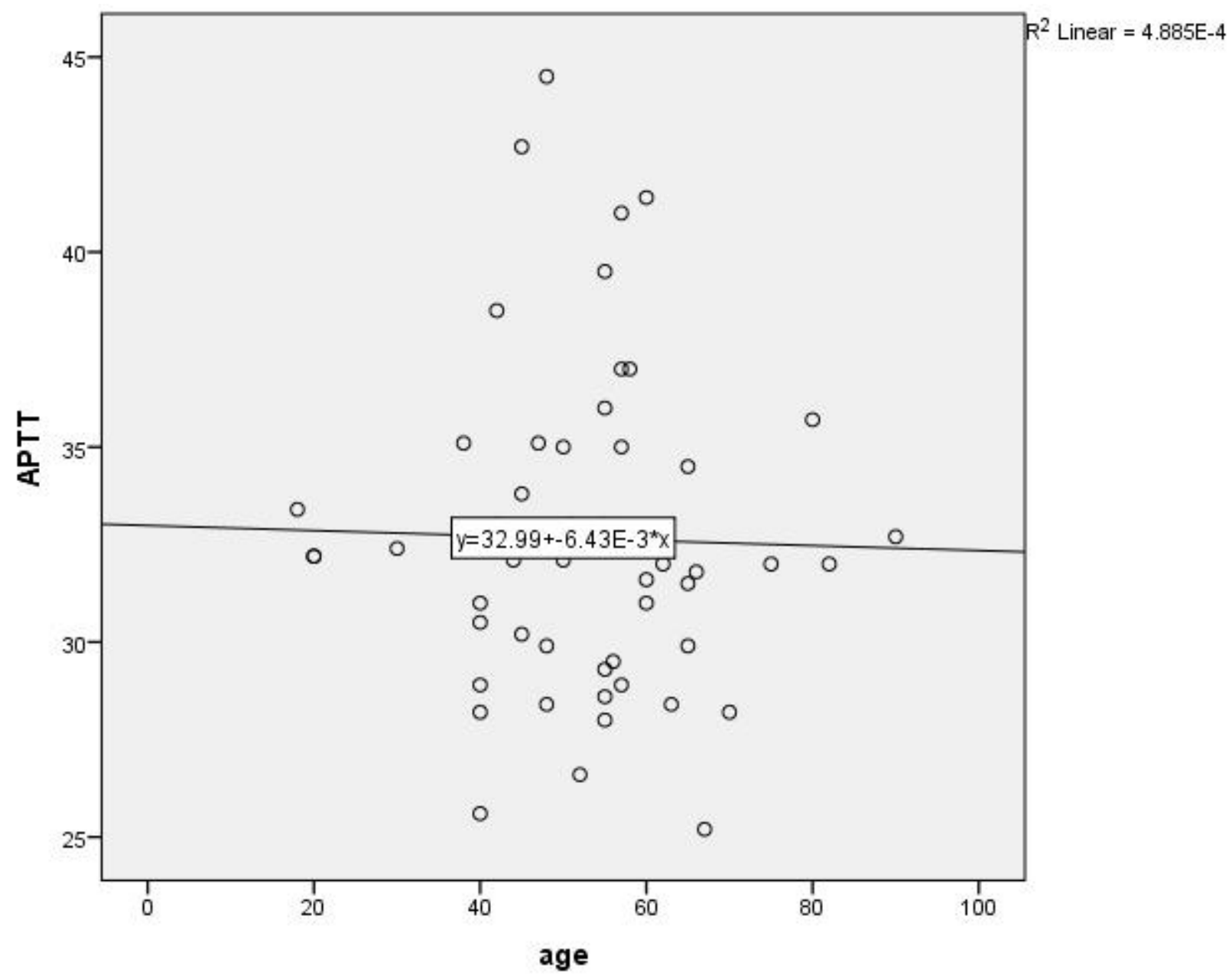

Figure 3. Positive correlation between PTT result and age.

\section{Discussion}

Diabetes mellitus (DM) is metabolic diseases characterized by hyperglycaemia resulting from defects in insulin secretion, insulin action, or both. The incidence of cardiovascular disease due to thrombosis is $2-4$ folds greater in diabetic patients. Prothrombin time, activated partial thromboplastin time and platelet count are hematological indices that give an insight into the coagulation status [6]. This study aimed to Evaluation of PT and APTT In Diabetes Mellitus in Khartoum State. In the present study, there is insignificant association between PT and management, hypertension, treatment and gender p. value $(0.193,0.55,0.20$ and 0.49$)$, respectively. These findings strongly agreed with the results of a study in Sudanese diabetic patients by [7], which showed that PT was insignificant in patients of all duration of disease, also showed PT was insignificant in patients with different ages (p. value was 0.191) and PT had insignificant variation with in diabetic patients with and without treatment $p$. value was $(0.178)$ also APTT insignificant with gender $p$. value was $(0.905)$ and with treatment $p$. value was (0.267). This study finding showed that there was insignificant difference of APTT and management, hypertension, treatment and gender $p$. value $(0.197,0.34,0.39,0.21)$ respectively. This study similar agreed with many studies which done by Soltani et al. [8] and Uhl and Bunsignore [9]. The current study also showed that there was in significant difference of the mean PT, APTT within normal ranges. PT was $(17 \pm 3.8 \mathrm{sec})$ and APTT was $(32.6 \pm 4.1 \mathrm{sec})$, this similar to the study done by Soltani et al. [8] in Ethiopia, showed that PTT was $(32.8 \pm 4.1$ sec). Similarly, studies conducted in Iran by [9], and in Nigeria by [10], reported in significant difference of PT findings among the groups. In this study, the mean of fibrinogen level among study participates was $136.3 \mathrm{mg} / \mathrm{dl}$ indicate to low level due to medications or lifestyle modifications this finding similar to Shoh [11]. In this study, the relation between plasma fibrinogen level and the age of diabetic type II patients there was in significant 
association $(p=0.329)$. In the present study, the level of plasma fibrinogen among diabetic type II patients according to the gender was insignificant difference $(\mathrm{p}$. value $=0.594)$. This result was similar to study conducted in Sudan, that found the Fibrinogen level was significantly higher in diabetic type II patients, with no difference between males and females, P. value $>0.05$. The current study was disagreement with studies that found plasma fibrinogen levels were higher among type 2 diabetes mellitus patients $(656 \mathrm{mg} / \mathrm{dl})$ as compared to controls $(324 \pm$ $139 \mathrm{mg} / \mathrm{dl}$ ) which were statistically significant different $\mathrm{p}$. value $<0.01$. This study was in not similar with other American study found that the mean plasma level of fibrinogen in the type II diabetics was higher than that of the normal population. This study was in agreement with study done by [11], which found the mean of D-dimer level among all patients was $2,037 \mathrm{ng} / \mathrm{mL}$. According to gender, the males and females were showed $1,859 \mathrm{ng} / \mathrm{mL}$ and $2,295 \mathrm{ng} / \mathrm{mL}$ respectively. No significant correlations were found.

\section{Conclusion}

The present study show that shortened prothrombin time, activated partial thromboplastin time, shortened PT and APTT might be useful hemostatic markers in diabetic patients, especially in those at high risk for thrombotic complications. The Mean of plasma fibrinogen level in patient with type II diabetics mellitus were $136.3 \mathrm{mg} / \mathrm{dl}$, insignificant correlation with Fibrinogen levels with age, gender and duration of disease. The D. Dimer level shows significant increase.

\begin{tabular}{cc} 
List of Abbreviation & \\
\hline Term & Abbreviation \\
\hline Diabetes mellitus & DM \\
Von Willebrand factor & Vwf \\
platelet glycoprotein complexes I & Gp-1b \\
tissue factor & TF \\
High molecular weight & HMW \\
Prothrombin time & PT \\
statistical package for social sciences & Spss \\
Activated partial prothrombin time & APTT \\
International normalized ratio & INR \\
Tissue plasminogen activator & TPA \\
Insulin Dependent Diabetes Mellitus & IDDM \\
Non Insulin Dependent Diabetes Mellitus & NIDDM \\
hemoglobin Alc & HA1C \\
Americans with disabilities act & ADA \\
Blood urea nitrogen & BUN \\
World health organization & WHO \\
Diabetes control and complications trial & DCCT \\
\hline
\end{tabular}

\section{Acknowledgement}

By the grace of Almighty Alla and his help I complete this study, all praise to him, my gratitude goes to Dr Enaam A, Rhman and Dr Khalid M, Khalid my supervisors whose guides me to complete this work, finally special thanks to patients who were so cooperative and despite their pain.

\section{References}

[1] Achneck, H. E., Sileshi, B., Parikh, A., Milano, C. A., Welsby, I. J., Lawson, J. H. (2010). Pathophysiology of bleeding and clotting in the cardiac surgery patient: From vascular endothelium to circulatory assist device surface. Hill, pp. 210-216.

[2] Thornton, P., Douglas, J. (2010). Coagulation in pregnancy. Best practres clinobstet gynaecol., 24: 339-52. 
[3] Previtali, E., Bucciarelli, P., Passamonti, S. M., Martinelli, I. (2011). Risk factors for venous and arterial thrombosis. Blood transfus., 9: 120-38.

[4] Mcfarlane, I. A. (1997). Endocrine disease and diabetes mellitus. In Williams, J. C. (ed.), textbook of diabetes (2nd edition) Oxford: Blackwell, pp. 640-660.

[5] Alvin, C. P. (2001). Diabetes. In: Principles of Internal Medicine, Braunwald E. Fauci Causes: As, Kasper, D. L., Havser, S. L., Longo, D. L., Jambon, J. L.: Harrinson (eds), 15 edition, USA, New York, Mcgraw. Hill, pp. 2109-2138.

[6] Bilous, R. and Donnelly, R. (2010). Handbook of diabetes. John Wiley \& Sons. Cdc.gov. (2019). [online] available at: https: //www.cdc.gov/media/presskits/aahd/diabetes.pdf.

[7] Lippi, G., Salvagno, G. L., Ippolito, L., Franchini, M., Favaloro, E. J. (2010). Shortened activated partial thromboplastin time: Causes and management. Blood Coagulofibrinolysis, 21: 459-463.

[8] Soltani, J. E., Sicree, R. A., Zimmet, P. Z. (2010). Who global estimates of the prevalence of diabetes for 2010. Diabetes Research and Clinical Practice, 87(1): 4-14.

[9] Uhl, E. and Bunsignore, P. (2006). Diabetes self-management education for children: General principles and practical application. Diabetes Spect, 19: 234-250.

[10] Ifeanyi, O. E., Chukwuemeka, O. H., Sunday, A. G., Uche, E. C. (2014). Changes in some coagulation parameters among diabetic patients in michaelokpara, University of Agriculture, Umudike, Abia State, Nigeria. World Journal of Pharmacy and Pharmaceutical Sciences, 3(4): 52-61.

[11] Shoh, I. A. (2007). Endocrine disease and diabetes mellitus. In Williams, J. C. (ed.), textbook of diabetes (2nd edition). Oxford: Black well, pp. 640-660.

[12] Noha Musa Abdulla, Tariq. E. Elmissbah, Esra Mohammed Hamid, Fatima Osman A-Ltom, and Maisa Faisal Abusham. (2017). International Journal of Multidisciplinary and Current Research. 